\title{
Expression of cell cycle-related proteins in oropharyngeal squamous cell carcinoma based on human papilloma virus status
}

\author{
KOUDAI TSUCHIDA ${ }^{1,2}$, TAMOTSU SUGAI $^{1}$, NORIYUKI UESUGI ${ }^{1}$, KAZUYUKI ISHIDA $^{1}$, \\ KAZUTO MATSUURA ${ }^{3}$, IKURO SATO ${ }^{4}$, KIYOTO SHIGA ${ }^{2}$ and HIROAKI SATO ${ }^{2}$ \\ Departments of ${ }^{1}$ Molecular Diagnostic Pathology, ${ }^{2}$ Otolaryngology-Head and Neck Surgery, \\ School of Medicine, Iwate Medical University, Morioka, Iwate 020-8505; Departments of ${ }^{3}$ Head and \\ Neck Surgery, ${ }^{4}$ Pathology, Miyagi Cancer Center, Natori, Miyagi 981-1293, Japan
}

Received December 22, 2016; Accepted May 15, 2017

DOI: $10.3892 /$ or.2017.5720

\begin{abstract}
The molecular association between human papilloma virus (HPV) and cell cycle-related (CCR) proteins is not fully understood in oropharyngeal squamous cell carcinoma (OPSCC). Herein, we examined the expression levels of CCRs in OPSCCs based on HPV status. In situ hybridization (ISH)- and polymerase chain reaction (PCR)based assays were used to detect HPV status in 98 OPSCCs, and CCRs were detected by immunostaining. Of 98 tumors, 47 had HPV-positive tumors by either ISH- or PCR-based assays. Concordance analysis between ISH- and PCR-based tests showed a good agreement in OPSCC. Expression of p16 was moderate, consistent with HPV positivity as determined by ISH-based analysis. High p53-, phospho (p)-Rb-, SKP2-, cyclin D1-, and p-c-myc-positive rates were correlated with HPV-negative tumors, whereas high p16- and p27-positive rates were associated with HPV-positive tumors. The positive rates for $\mathrm{p} 21$ and cyclin A did not differ between HPV-positive and HPV-negative tumors. Finally, Ki-67 positivity was commonly observed for both types of OPSCCs. Although expression of p16 is thought to be a marker of HPV infection, ISH- or PCR-based tests should be used for HPV detection. In addition, our results regarding CCRs may be helpful for understanding the carcinogenesis of OPSCC.
\end{abstract}

\section{Introduction}

Head and neck cancer (HNC), including cancers of the oropharynx, larynx, hypopharynx, and sinonasal tract, is the sixth most common cancer worldwide (1). In addition, HNC

Correspondence to: Professor Tamotsu Sugai, Department of Molecular Diagnostic Pathology, School of Medicine, Iwate Medical University, 19-1 Uchimaru, Morioka, Iwate 020-8505, Japan

E-mail: tsugai@iwate-med.ac.jp

Key words: cell cycle-related protein, human papilloma virus, oropharyngeal cancer, p16, p53, p-Rb, cyclin D1 is notoriously difficult to treat, and treatment is often associated with serious side effects (2). Although these cancers are linked by common clinicopathological findings, including male predominance, heavy smoking, habitual alcohol use, and common histological features (squamous cell carcinoma), some types of HNC are known to have specific etiologies (3). Oropharyngeal squamous cell carcinoma (OPSCC) is a specific type of HNCs often caused by human papilloma virus (HPV) infection, as demonstrated in recent studies (1,4-6). Moreover, of HNCs, the carcinogenesis of OPSCC has been well characterized (4-7).

Although most studies have demonstrated that OPSCC can be caused by factors known to cause various types of HNCs $(3,4)$, HPV infection has been increasingly recognized as a major etiological factor for OPSCC (4-7). Additionally, HPV-induced OPSCC shows distinct epidemiologic, clinical, and molecular alterations (8-10). Thus, the presence/absence of HPV may influence therapy or outcomes in patients with OPSCC (11). In addition, this observation suggests that eradication of HPV could prevent OPSCC (11). Accordingly, detection of HPV is the first step for evaluation of the pathological role of HPV infection in OPSCC. In situ hybridization (ISH)- and polymerase chain reaction (PCR)-based assays have been used to detect HPV in tumor cells in most previous studies (12-14). However, the results of ISH-based tests are not always consistent with those of PCR-based tests (1). Thus, determining the concordance between these methods will be important for identifying the molecular role of HPV infection in tumor cells.

Cancer is a disease of uncontrolled cell division (15-17). Its development and progression are usually linked to a series of changes in the activities of cell cycle regulators, which can be classified as positive or negative regulators (15-17). Common positive regulators of the cell cycle include cyclin A and cyclin D1, which promote the progression of the cell cycle to the next phase; in contrast, Rb, p16, p53, p21, and p27 are negative regulators that inhibit the progression of the cell cycle to the $S$ phase (16-18). In addition to these proteins, SKP2 has also been identified as a novel factor controlling the cell cycle $(18,19)$. Abnormal expression of these cell cycle-related proteins is frequently found in various cancers, including not only OPSCC but also gastric, breast, lung, and colorectal cancers (20-24). However, the results of immunostaining for 
each of these cell cycle-related proteins vary within tumor tissues (20-24). For example, although positive regulators (e.g., cyclin A, cyclin D1, and SKP2) are usually overexpressed in cancer cells, negative regulators can exhibit either low expression (e.g., p21 and p27) or overexpression [e.g., phospho (p)-Rb and p53] (20-24). Ki-67 and p-c-myc proteins have been used as traditional markers of proliferative activity in tumor cells (25-27). Previous studies have shown that rates of $\mathrm{Ki}-67$ and p-c-myc expression in tumor cells are correlated with the $\mathrm{S}$-phase fraction, indicating that the expression levels of Ki-67 and p-c-myc are closely associated with the expression of cell cycle-related proteins (25-27). However, the roles of these cell cycle proteins have not been determined in HPV-positive or HPV-negative OPSCC.

The oncogenic nature of HPV can be explained by the transforming properties of HPV oncoproteins E6 and E7, which target the p53 and p-Rb tumor-suppressor pathways, respectively $(1,4)$. This finding suggests that E6 and E7 may render infected cells susceptible to mutations and cancer development. In addition, the oncogenic nature of HPV may be associated with abnormalities in cell cycle-related proteins. Our aim is to determine the possible association of OPSCC with HPV and to better characterize the immunoprofile, with special emphasis on the expression of cell cycle-related proteins.

\section{Materials and methods}

Patients. We included specimens of OPSCC $(\mathrm{n}=98)$ collected at Iwate Medical University Hospital and Miyagi Prefectural Miyagi Cancer Center from 1996 to 2016. The tumor specimens were retrospectively obtained from pathology laboratories, and histological diagnosis was performed based on the General Rules for Clinical Studies on Head and Neck Cancer (28). Histological classification was not examined according to HPV status. Clinicopathological data are shown in Table I. Our study was approved by the ethics committees of Iwate Medical University (approval no. H27-126) and Miyagi Cancer Center (approval no. 27-85). All procedures performed in studies involving human participants were in accordance with the ethical standards of the institutional and national research committee and with the 1964 Declaration of Helsinki and its later amendments or comparable ethical standards. Informed consent was obtained from all individual participants included in the study.

Sample preparation of pathological tissue. Serial sections were cut to a thickness of $3 \mu \mathrm{m}$ and mounted on positively charged glass slides for ISH. Paraffin sections were cut from each block ( 3 sections, $10 \mu \mathrm{m}$ ) for DNA extraction. The extra sections cut before and after each tissue section were stained with hematoxylin and eosin (H\&E) and used to determine specimen quality for testing. To avoid cross-contamination, the microtome was cleaned and a new blade was used for each sample.

Preparation of digital slides for OPSCC specimens. Digital images of the OPSCC specimens were acquired (Aperio ScanScope; Leica Biosystem Imaging, Wetzlar, Germany). Detection of HPV was carried out using digital image slides.
Table I. Clinicopathological findings of oropharyngeal carcinoma examined.

\begin{tabular}{|c|c|}
\hline Characteristics & Number $(\%)$ \\
\hline Total & $98(100)$ \\
\hline \multicolumn{2}{|l|}{ Sex } \\
\hline Male & $86(87.8)$ \\
\hline Female & $12(12.2)$ \\
\hline \multicolumn{2}{|l|}{ Age (years) } \\
\hline Median (range) & $65(33-83)$ \\
\hline \multicolumn{2}{|l|}{ Tumor subsites } \\
\hline LW & $63(64.3)$ \\
\hline AW & $19(19.4)$ \\
\hline SW & $11(11.2)$ \\
\hline PW & $5(5.1)$ \\
\hline \multicolumn{2}{|l|}{ Differentiation } \\
\hline Well & $26(26.5)$ \\
\hline Moderate & $47(48.0)$ \\
\hline Poor & $25(25.5)$ \\
\hline \multicolumn{2}{|l|}{ Nodal status } \\
\hline No & $45(45.9)$ \\
\hline N1-3 & $53(54.1)$ \\
\hline \multicolumn{2}{|l|}{ Tumor stage } \\
\hline I & $16(16.3)$ \\
\hline II & $22(22.5)$ \\
\hline III & $12(12.2)$ \\
\hline IV & $48(49.0)$ \\
\hline
\end{tabular}

$\mathrm{LW}$, lateral wall; $\mathrm{AW}$, anterior wall; $\mathrm{SW}$, superior wall; $\mathrm{PW}$, posterior wall.

Assessments of ISH for HPV and immunohistochemical examination for cell cycle-related proteins were performed using digital images. The positive rates (PRs) in tumor tissues were measured within the hot spot area on the slide. At the hot spot area, the PR was calculated as the percentage using automated measuring software (Aperio image scope 12.0.1).

ISH for HPV. Probe sets able to detect 12 types of oncogenic HPV $(16,18,31,33,35,39,45,51,52,56,58$, and 66) were obtained from Roche Medical Systems (INFORM ${ }^{\circledR}, 12$ Highrisk HPV Genotype kit). ISH was performed according to the manufacturer's guidelines using a Roche automated slide staining system (Roche Medical System) (12). HPV control slides consisted of formalin-fixed, paraffin-embedded sections containing three separate collections of cells on a single slide (Roche Medical Systems). These cells consisted of the CaSki cervical cancer cell line (containing 200-400 copies of HPV16 per cell); the HeLa cervical cancer cell line (containing 10-50 copies of HPV18 per cell); and the $\mathrm{C}-33 \mathrm{~A}$ cell line, which served as a negative control. The negative control was set using negative control probes provided by Ventana Medical Systems. 
Table II. Concordance of ISH- and PCR-based assays in OPSCC.

\begin{tabular}{|c|c|c|c|c|c|}
\hline & \multicolumn{3}{|c|}{ PCR } & \multirow[b]{2}{*}{ P-value } & \multirow[b]{2}{*}{$\kappa$} \\
\hline & Total & Positive & Negative & & \\
\hline \multicolumn{6}{|l|}{ HPV-ISH } \\
\hline Total & 98 & 46 & 52 & & \\
\hline Positive & 30 & 29 & 1 & & \\
\hline Negative & 68 & 17 & 51 & $<0.001$ & 0.62 \\
\hline
\end{tabular}

Nuclear staining was considered a positive result for HPV DNA. Two nuclear staining patterns, diffuse staining and dotlike staining, were primarily observed in the tumor tissues. All staining patterns were defined as positive signals. HPV positivity was determined using a $10 \%$ cutoff (29).

Two pathologists independently reviewed the INFORM slides. In some cases in which the evaluation provided different results, a consensus interpretation was reached after re-examination.

DNA extraction from paraffin-embedded sections. DNA from normal and tumor tissue was extracted by standard SDS proteinase $\mathrm{K}$ treatment. DNA extracted from the samples was resuspended in TE buffer [10 $\mathrm{mM}$ Tris-HCl, $1 \mathrm{mM}$ EDTA (pH 8.0)].

Detection of HPV by Cobas 4800 assays. Cobas tests were carried out according to the manufacturer's protocol (31). DNA extraction was accomplished using a fully automated Cobas x 480 instrument. Briefly, specimens were digested under denaturing conditions at elevated temperatures and then lysed in the presence of chaotropic reagent. Released HPV nucleic acids, along with $\beta$-globin DNA as a process control, were purified through adsorption to magnetic glass particles, washed, separated from the particles, and subjected to PCR amplification and detection.

The amplification plates were then manually transferred to the Cobas z 480 analyzer for real-time PCR amplification of high-risk HPV and $\beta$-globin DNA. The Cobas HPV test uses primers that define a sequence of approximately 200 nucleotides within the polymorphic L1 region of the HPV genome, as previously described. A pool of HPV primers present in the master mix was designed to amplify HPV DNA from 14 highrisk types $(16,18,31,33,35,39,45,51,52,56,58,59,66$, and 68). Fluorescent oligonucleotide probes were used to bind to the polymorphic regions within the sequence defined by the primers. An additional primer pair and probe targeting the human $\beta$-globin gene (330-bp amplicon) was included as an internal control to provide a measure of specimen adequacy and to monitor the quality of the extraction and amplification process. Interpretation of amplification results was performed using proprietary software provided with the Cobas z 480 analyzer. The cycle threshold cutoffs were set at 40.5 for HPV16 and 40 for HPV18 and for the remaining 12 high-risk HPV genotypes. Positive and negative controls were included in each run.
Table III. Clinicopathological findings of oropharyngeal carcinoma according to the HPV status.

\begin{tabular}{|c|c|c|c|c|}
\hline \multirow[b]{2}{*}{ Factors } & \multirow[b]{2}{*}{$\begin{array}{c}\text { Total } \\
(\%)\end{array}$} & \multicolumn{2}{|c|}{ HPV-status } & \multirow[b]{2}{*}{ P-value } \\
\hline & & $\begin{array}{c}\text { Positive } \\
(\%)\end{array}$ & $\begin{array}{c}\text { Negative } \\
(\%)\end{array}$ & \\
\hline No. of cases & $98(100)$ & $47(100)$ & $51(100)$ & \\
\hline Sex & & & & NS \\
\hline Male & $86(87.8)$ & $40(85.1)$ & $46(90.2)$ & \\
\hline Female & $12(12.2)$ & $7(14.9)$ & $5(9.8)$ & \\
\hline \multicolumn{5}{|l|}{ Age (years) } \\
\hline Median (range) & $65(33-83)$ & $62(36-83)$ & $67(33-83)$ & $<0.01$ \\
\hline \multicolumn{5}{|l|}{ Tumor subsites } \\
\hline LW & $63(64.3)$ & $39(83.0)$ & $24(47.1)$ & $<0.001$ \\
\hline AW & $19(19.4)$ & $3(6.4)$ & $16(31.4)$ & $<0.01$ \\
\hline SW & $11(11.2)$ & $4(8.5)$ & $7(13.7)$ & NS \\
\hline PW & $5(5.1)$ & $1(2.1)$ & $4(7.8)$ & NS \\
\hline \multicolumn{5}{|l|}{ Differentiation } \\
\hline Well & $26(26.5)$ & $8(17.0)$ & $18(35.3)$ & $<0.05$ \\
\hline Moderate & $47(48.0)$ & $25(53.2)$ & $22(43.1)$ & NS \\
\hline Poor & $25(25.5)$ & $14(29.8)$ & $11(21.6)$ & NS \\
\hline Nodal status & & & & $<0.05$ \\
\hline No & $45(45.9)$ & $16(34.0)$ & $29(56.9)$ & \\
\hline $\mathrm{N} 1-3$ & $53(54.1)$ & $31(66.0)$ & $22(43.1)$ & \\
\hline Tumor stage & & & & NS \\
\hline I & $16(16.3)$ & $3(6.4)$ & $10(19.6)$ & \\
\hline II & $22(22.5)$ & $11(23.4)$ & $13(25.5)$ & \\
\hline III & $12(12.2)$ & $6(12.8)$ & $6(11.7)$ & \\
\hline IV & $48(49.0)$ & $27(57.4)$ & $21(41.2)$ & \\
\hline
\end{tabular}

HPV, human papilloma virus; NS, not significant; LW, lateral wall; $\mathrm{AW}$, anterior wall; SW, superior wall; PW, posterior wall.

Assessment of HPV positivity in tumor cells. HPV was defined as positive if either the ISH-based test or the PCR-based test was positive or if both tests were positive within the given section. HPV was defined as negative if both tests were negative.

Immunohistochemistry of tumor tissue sections. Tissues for analysis were fixed for several hours in $10 \%$ neutral buffered formalin and then embedded in paraffin. Paraffin sections $(3 \mu \mathrm{m})$ were routinely dewaxed and rehydrated, then subjected to heat-induced epitope retrieval in either High $\mathrm{pH}$ Target Retrieval solution (Dako, Carpinteria, CA, USA) or Reveal Decloaking solution (BioCare Medical, Concord, MA, USA) for $8 \mathrm{~min}$, and then incubated with primary antibody for $90 \mathrm{~min}$ (21). The following antibodies were used in this analysis: anti-p16 (clone E6H4, ready-to-use; Roche Diagnostics, Basel, Switzerland), anti-p53 (clone DO7, 1:100 dilution; Neomarkers Inc., Fremont, CA, USA), anti-p-Rb (polyclonal, 1:300 dilution; Cell Signaling Technology, 


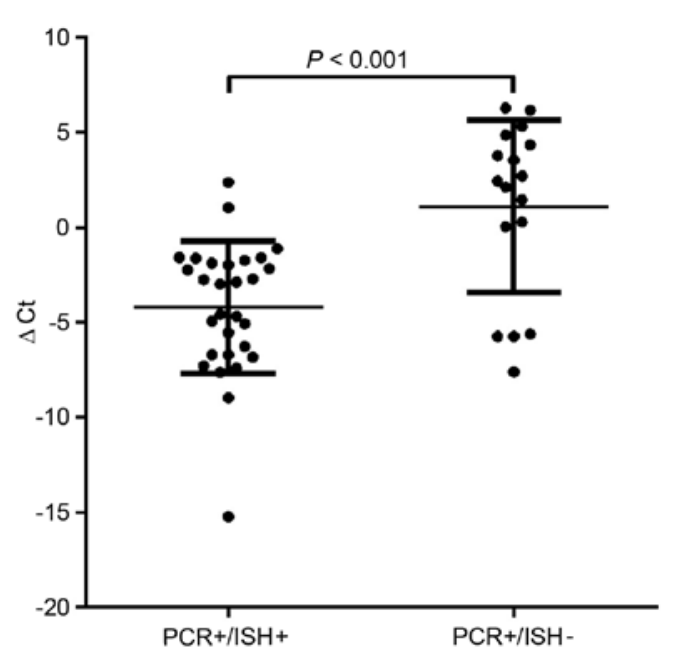

Figure 1. Comparison of viral loads of OPSCC with $\mathrm{PCR}^{+} / \mathrm{ISH}^{+}$and $\mathrm{PCR}^{+} / \mathrm{ISH}^{-}$.

Beverly, MA, USA), anti-p21 (clone SX118, 1:50 dilution; Dako), anti-p27 (clone SX53G8, 1:50 dilution; Dako), antiSKP2 (polyclonal, 1:50 dilution; Santa Cruz Biotechnology, Santa Cruz, CA, USA), anti-cyclin D1 (clone SP4, 1:100; Nichirei, Tokyo, Japan), anti-cyclin A (clone, 6E8, 1:100; Novocastra, Newcastle, UK), anti-p-c-myc (clone, 33A12E10, 1:50; Abcam, Cambridge, UK), and anti-Ki-67 (clone MIB1, ready-to-use; Dako). After primary antibody treatment, sections were analyzed using the EnVision Plus Mouse HRP detection system (Dako), and antigen binding was detected using DAB+ liquid chromogen (Dako). Sections were then counterstained with hematoxylin before mounting. Assessment of the expression of each marker was carried out within the hot spot of each marker.

Statistical analysis. Clinicopathological findings were analyzed using Chi-square tests (Stat Mate for Windows version 3.07; Atom, Tokyo, Japan). Differences in the frequencies of immunohistochemical expression of cell cycle-related proteins between HPV-positive and HPV-negative OPSCC were analyzed using Mann-Whitney U tests (GraphPad Prism 6; MDF, Tokyo, Japan). Differences with P-values of $<0.05$ were considered to indicate a statistically significant difference.

\section{Results}

Staining patterns of HPV and INFORM for detection of $H P V$. Positive staining for HPV varied within the same tumor (i.e., exhibiting a heterogeneous staining pattern). Although diffuse HPV staining was observed in 12 of 30 tumors (40\%), heterogeneity of staining was found in 18 of 30 tumors $(60 \%)$. Overall, HPV was positive in 30 of 98 tumors $(30.6 \%)$ when using ISH as the detection method.

Detection of HPV using a PCR-based assay. Although the most frequent HPV subtype detected by PCR-based assay was HPV subtype 16 (41 of 46 HPV-positive tumors, 89.1\%), HPV subtype 18 was rarely detected in OPSCCs (1 of 46 HPV-positive tumors, $2.2 \%$ ). The frequency of HPV for subtypes other than 16 and 18 was $8.7 \%$ (4 of 46 HPV-positive tumors).
Table IV. Clinicopathological differences between $\mathrm{PCR}^{+} / \mathrm{ISH}^{-}$ and $\mathrm{PCR}^{+} / \mathrm{ISH}^{+}$cases.

\begin{tabular}{|c|c|c|c|}
\hline \multirow[b]{2}{*}{ Factors } & \multicolumn{2}{|c|}{ HPV type 16 + OPSCC } & \multirow[b]{2}{*}{ P-value } \\
\hline & $\mathrm{PCR}^{+} / \mathrm{ISH}^{+}$ & $\mathrm{PCR}^{+} / \mathrm{ISH}^{-}$ & \\
\hline Cases & 27 & 14 & \\
\hline Sex & & & NS \\
\hline Male & 24 & 12 & \\
\hline Female & 3 & 2 & \\
\hline Age & & & NS \\
\hline Median & $60(36-83)$ & $63.5(43-76)$ & \\
\hline \multicolumn{4}{|l|}{ Tumorsubsites } \\
\hline LW & 26 & 8 & $<0.01$ \\
\hline AW & 1 & 1 & \\
\hline SW & 0 & 4 & $<0.05$ \\
\hline PW & 0 & 1 & \\
\hline Differentiation & & & NS \\
\hline Well & 2 & 5 & \\
\hline Moderate & 15 & 8 & \\
\hline Poor & 10 & 1 & \\
\hline Nodal status & & & $<0.01$ \\
\hline No & 5 & 10 & \\
\hline $\mathrm{N} 1-3$ & 22 & 4 & \\
\hline Stage & & & NS \\
\hline I & 0 & 3 & \\
\hline II & 4 & 5 & \\
\hline III & 4 & 1 & \\
\hline IV & 19 & 5 & \\
\hline
\end{tabular}

HPV, human papilloma virus; NS, not significant; LW, lateral wall; $\mathrm{AW}$, anterior wall; SW, superior wall; $\mathrm{PW}$, posterior wall.

Comparison of ISH-and PCR-based assays. The concordance between ISH- (INFORM) and PCR-based assays in the detection of HPV DNA is shown in Table II. The two tests were concordant in $81.6 \%$ ( 80 of 98 ) of cases (29 positive cases and 51 negative cases). The INFORM and PCR-based assays had good agreement (Kappa coefficient of 0.62) in detecting HPV DNA in OPSCC. HPV positivity in OPSCC, as determined by combined ISH- and PCR-based assays, was 48.0\% (47/98; positive in either ISH- or PCR-based assays). This positivity was regarded as overall HPV positivity in this study. These results are summarized in Table II.

The OPSCC specimens examined in this study were classified as HPV positive (+) or HPV negative (-). There were significant differences in median age $(\mathrm{P}<0.01)$, tumor location $(\mathrm{P}<0.01)$, tumor differentiation $(\mathrm{P}<0.05)$, and lymph node metastasis $(\mathrm{P}<0.05)$ between HPV $(+)$ and HPV $(-)$ samples. No differences in histological features were observed in the OPSCC specimens examined. Clinicopathological findings for these two groups are listed in Table III. 
A

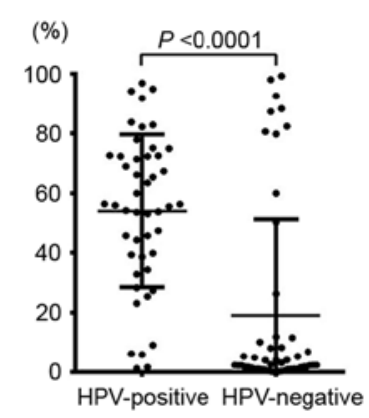

F

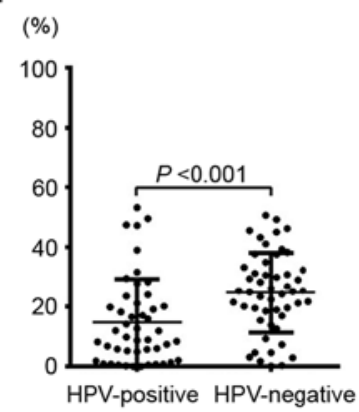

B

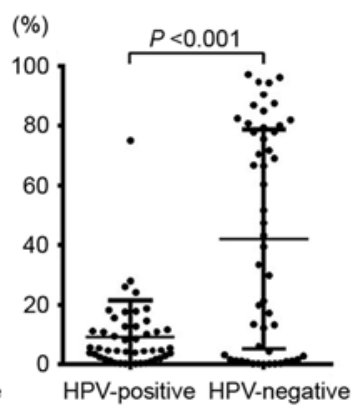

G

(\%)

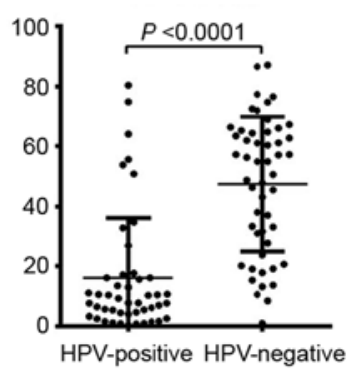

C

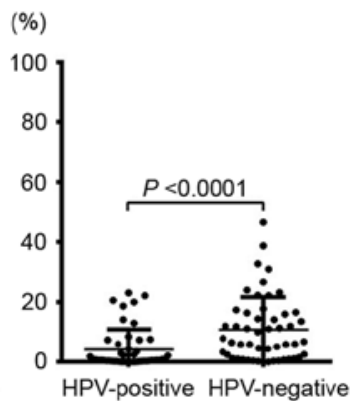

H

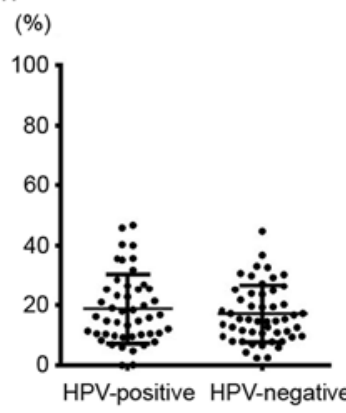

D

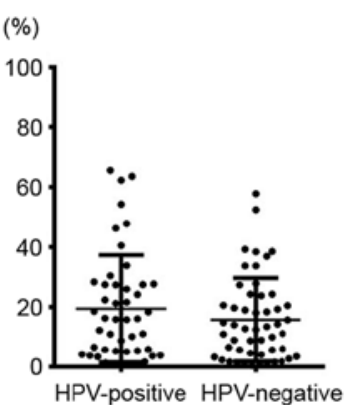

(\%)

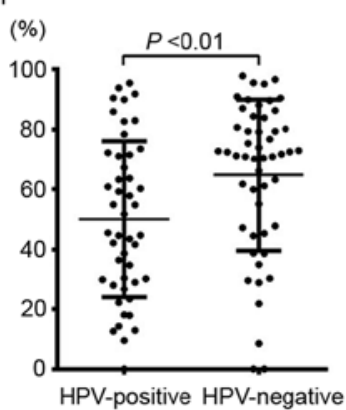

E

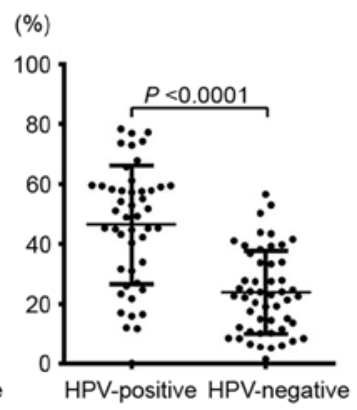

(\%)

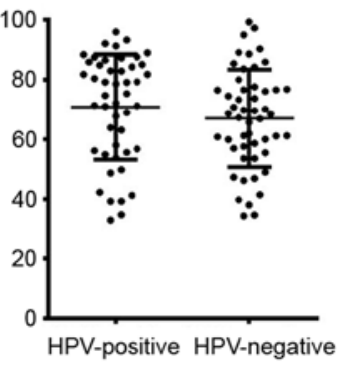

Figure 2. Distribution of positive rates for each cell cycle-related marker. (A) p16, (B) p53, (C) p-Rb, (D) p21, (E) p27, (F) SKP2, (G) cyclin D1, (H) cyclin A, (I) p-c-myc, (J) Ki-67.

Measurement of viral load (HPV) between $\mathrm{PCR}^{+} / \mathrm{ISH}^{-}$and $P C R^{+} / I S H^{+}$. We next examined the viral load (HPV) using real-time $\mathrm{PCR}$ in $\mathrm{PCR}^{+} / \mathrm{ISH}^{-}$and $\mathrm{PCR}^{+} / \mathrm{ISH}^{+}$tumor cells using the $\Delta \mathrm{Ct}$. The results showed that the viral loads in tumor cells with $\mathrm{PCR}^{+} / \mathrm{ISH}^{+}$increased compared with those with $\mathrm{PCR}^{+} / \mathrm{ISH}^{-}(\mathrm{p}<0.001$; Fig. 1). In addition, we examined the clinicopathological differences between $\mathrm{PCR}^{+} / \mathrm{ISH}^{-}$and $\mathrm{PCR}^{+} / \mathrm{ISH}^{+}$cases. In this study, oropharyngeal squamous cell carcinoma with $\mathrm{PCR}^{+} / \mathrm{ISH}^{+}$was preferentially located at the lateral wall of the oropharyngeal region compared with that of $\mathrm{PCR}^{+} / \mathrm{ISH}^{-}$. Finally, the frequency of lymph node metastasis was significantly higher in $\mathrm{PCR}^{+} / \mathrm{ISH}^{+}$tumors than in $\mathrm{PCR}^{+} / \mathrm{ISH}^{-}$tumors. These findings are summarized in Table IV.

Association of p16 expression with HPV status. Most tumors exhibited intense, diffuse p16 expression in both the nucleus and cytoplasm. The positive cutoff value for p16 expression was defined as $>30 \%$ of tumor cells. p16 expression and HPV status were both positive in 37 of 98 tumors $(37.8 \%)$ by PCR-based assays, whereas that by ISH-based assays was 27 of 98 (27.6\%), as shown in Table V-A and V-B. The overall concordance of p16 expression and HPV status (as determined by both ISH- and PCR-based tests) was 38 of 98 (38.8\%), with $38 \mathrm{HPV}(+)$ cases and $41 \mathrm{HPV}(-)$ cases, as shown in Table $\mathrm{V}-\mathrm{C}$. The concordance of p16 expression and HPV positivity by PCR-based and ISH assays was moderate ( $\kappa$ values of 0.51 and 0.59 , respectively), consistent with the combined HPV DNA positivity observed by INFORM and PCR-based assays ( $\kappa$ value, 0.61). The HPV-positive area, as determined using ISH, was observed within the p16 expression area. Therefore, the area of p16 staining was larger than that of HPV positivity.
Assessment of Ki-67, p-c-myc, SKP2, and cell cycle-related proteins (p53,p21,p27, p-Rb, cyclin D1, and cyclin A) in tumor tissue sections based on HPV status. Although p16 expression was observed in both the nucleus and cytoplasm, as mentioned above, Ki-67, p-c-myc, SKP2, p53, p21, p27, $\mathrm{p}-\mathrm{Rb}$, cyclin A, and cyclin D1 were only expressed in the nucleus in tumor cells. There were no significant differences in the PRs of Ki-67 between HPV (+) and HPV (-) cases of OPSCC. Although the PR of p27 expression was significantly higher in HPV (+) samples than in HPV (-) samples, the PRs of p53 overexpression and p-Rb, p-c-myc, and cyclin D1 levels were significantly higher in HPV (-) samples than in HPV (+) samples. In addition, the PR of SKP2 was significantly higher in HPV (-) OPSCC than in HPV (+) OPSCC. In contrast, the PRs of p21 and cyclin A expression did not differ significantly between HPV (+) and HPV (-) samples. These results are shown in Fig. 2. Representative immunohistochemical features based on HPV status are depicted in Figs. 3 and 4.

\section{Discussion}

The majority of studies have utilized HPV DNA ISH- or PCR-based methods for detection of HPV infection $(12,30,31)$. Although ISH- and PCR-based assays are generally concordant for HPV infection, it is important to assess commonly used methods for HPV detection. In this study, we observed that ISH assays using the INFORM probe were comparable to PCR-based assays with regard to detection of HPV DNA in formalin-fixed, paraffin-embedded tissues from patients with OPSCC. However, PCR-based assays could not be used to determine whether the HPV originated from the tumor cells or from adjacent non-tumor cells, leading to the concern that PCR-based assays may yield false-positive results (32). 


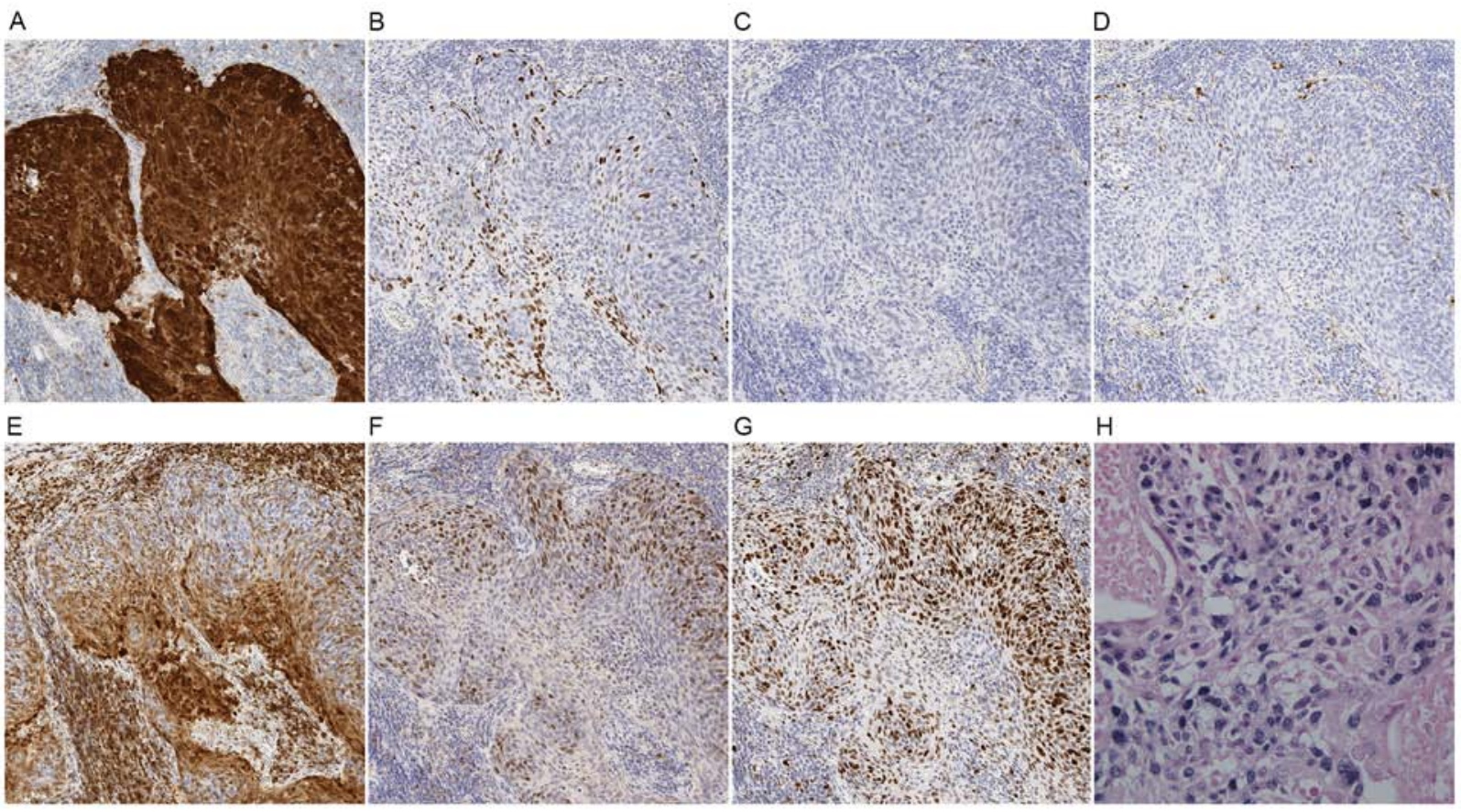

Figure 3. Representative examples of the expression patterns of cell cycle-related proteins in HPV-positive OPSCC. (A) Overexpression of p16. (B) Focal expression of p53. (C) Low expression of p-Rb. (D) Low expression of cyclin D1. (E) Overexpression of p27. (F) Low expression of SKP2. (G) Low expression of p-c-myc. (H) HPV-positivity detected by in situ hybridization.

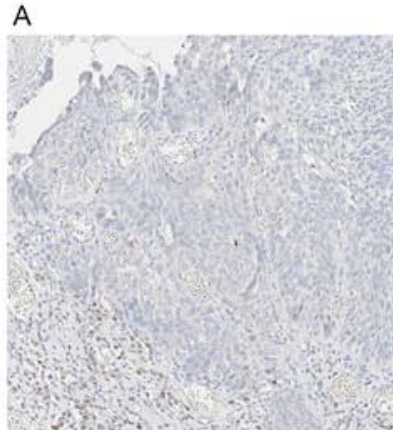

$\mathrm{E}$

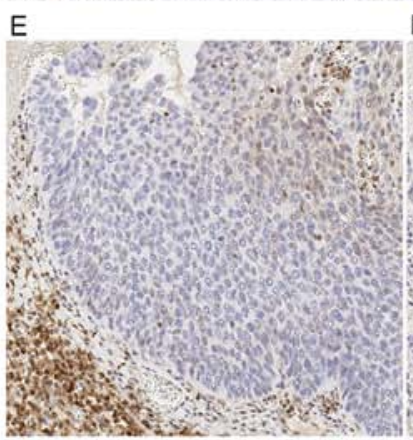

B

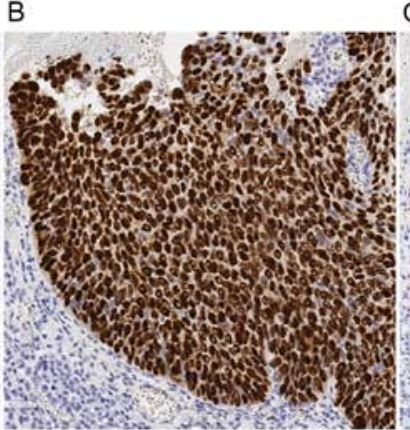

$F$

C

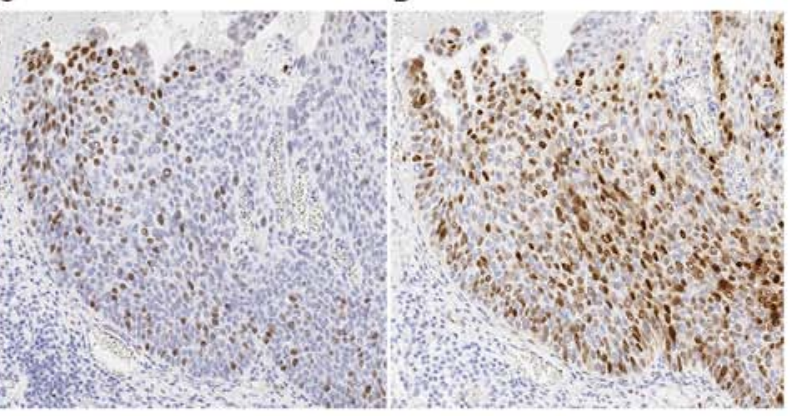

G

$H$

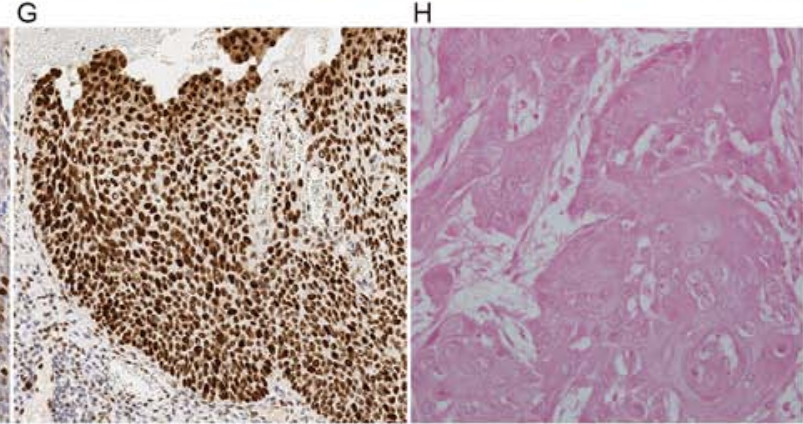

Figure 4. Representative examples of the expression patterns of cell cycle-related proteins in HPV-negative OPSCC. (A) Low expression of p16. (B) Strong overexpression of p53. (C) Expression of p-Rb. (D) Overexpression of cyclin D1. (E) Low expression of p27. (F) High expression of SKP2. (G) High expression of p-c-myc. (H) HPV-negativity detected by in situ hybridization.

Therefore, the use of ISH-based assays could overcome this limitation of PCR-based assays and provide more accurate results. Moreover, an important advantage of ISH is the ability to determine the cellular localization of HPV (32). However, both HPV DNA PCR- and ISH-based methods only evaluate the presence of HPV DNA in the sample and do not indicate whether the virus is transcriptionally active (32). Based on our analysis, we suggest that a combination of PCR- and ISH-based assays is required to accurately detect HPV infection in tumor cells, although active HPV may not be detected. Although false-positive results for HPV status between PCR-based and ISH assays may exist, we think that our definition of HPV positivity as positive in either ISH- or PCR-based assays is an appropriate criterion for determination of HPV status. This 
Table V. Concordance between HPV positivity and p16 expression in OPSCC.

\section{(A) HPV-ISH}

\begin{tabular}{lrrrrr}
\cline { 3 - 4 } & Total & Positive & Negative & P-value & $\kappa$ \\
\hline p16 & & & & & \\
Total & 98 & 30 & 68 & & \\
Positive & 48 & 27 & 21 & & \\
Negative & 50 & 3 & 47 & $<0.001$ & 0.51 \\
\hline
\end{tabular}

(B) PCR

\begin{tabular}{lrrrrr} 
& Total & Positive & Negative & P-value & $\kappa$ \\
\hline p16 & & & & & \\
Total & 98 & 46 & 52 & & \\
Positive & 48 & 37 & 11 & & \\
Negative & 50 & 9 & 41 & $<0.001$ & 0.59 \\
\hline
\end{tabular}

(C) HPV

Total Positive Negative P-value $\kappa$

\begin{tabular}{lrrrrr}
\hline p16 & & & & & \\
Total & 98 & 47 & 51 & & \\
Positive & 48 & 38 & 10 & & \\
Negative & 50 & 9 & 41 & $<0.001$ & 0.61 \\
\hline
\end{tabular}

finding is supported by a previous study in which the results of PCR-based assays were found to be correlated with those of ISH to measure the HPV viral load (33).

Heterogeneity within the same tumor is an important issue for tumor development. Therefore, intratumoral differences in HPV status within the same tumor are of interest. One explanation is that clonal differences occur within the tumor due to differences in time when viral infection occurs within the tumor. An alternative explanation is that there may be differences in biological sensitivity (e.g., immunosensitivity) between HPV (+) and HPV (-) cases, even within the same tumor. However, the reason for the heterogeneity of HPV status within OPSCC remains unknown.

Cell cycle progression can be accurately controlled to regulate cell proliferation $(15,16)$. Cellular proliferation is defined by regulation of cell cycle-related proteins, including the negative regulators $\mathrm{p} 53, \mathrm{p} 21, \mathrm{p} 27, \mathrm{p} 16$, and $\mathrm{p}-\mathrm{Rb}$ and the positive regulators cyclin A and cyclin D1 $(15,16,34)$. Thus, proliferative activity can be measured by determining the expression levels of Ki-67 and p-c-myc (25-27). In human cancer cells, expression of p53, p-Rb, cyclin D1, and cyclin A is thought to indicate a high rate of proliferation, whereas expression of $\mathrm{p} 21, \mathrm{p} 27$, and p16 is thought to indicate a low rate of proliferation (20). The present results suggested that low expression of $\mathrm{p} 53, \mathrm{p}-\mathrm{Rb}, \mathrm{p}-\mathrm{c}-\mathrm{myc}$, and cyclin D1, combined with high expression of p27 and p16, characterized the HPV-positive status and that opposite results characterized the HPV-negative status. Additionally, the expression of SKP2, which causes multi-ubiquitylation of p27, was high in HPV-negative tumors. However, the PR of Ki-67 in HPV-positive tumors was not different from that in HPV-negative tumors (35). In addition, in the present study, the PRs of cyclin A and p21 were not different between HPV-positive and HPV-negative tumors. The present results supported the notion that patients with OPSCC having HPV-positive tumors had better prognoses than patients with OPSCC having HPV-negative tumors. However, to the best of our knowledge, this is the first study reporting an extensive analysis of the association between cell cycle-related proteins and HPV status in patients with OPSCC.

Despite its function as a tumor suppressor, p16 expression is increased in HPV-positive OPSCC specimens, and there are strong correlations between HPV positivity and p16 expression in OPSCC specimens $(36,37)$. In the present study, the frequency of HPV positivity was concordant with p16 expression in OPSCC specimens. This result suggested that immunohistochemical expression of p16 could be a surrogate biomarker for prediction of HPV infection. p16 is thought to reflect the activity of the E7 oncoprotein of HPV, which disrupts the Rb pathway. HPV E7 oncoprotein binds to $\mathrm{p}-\mathrm{Rb}$, releasing E2F transcription factor, which activates DNA synthesis by promoting the transcription of genes involved in this process (38). As a consequence, p16 is strongly activated by these events, and immunoexpression of p16 has been used in the clinical setting as a surrogate for transcriptionally active HPV infection because the tumor-suppressive p16 protein is usually inactivated in HPV-negative OPSCC. Recent studies have shown that HPV infection is associated with survival in patients with OPSCC and that this factor can predict patient prognosis in OPSCC $(36,37)$. One possible explanation for the improved prognoses in patients with HPV-positive OPSCC is the high expression of p16 in these tumors $(36,37)$. Thus, we suggest that combined detection of p16 protein expression and the presence of HPV DNA is necessary for treating OPSCC.

A previous study showed that p16 expression is a powerful prognostic factor in patients with OPSCC. p16 positivity is associated with a survival benefit in these patients, independent of clinicopathological parameters such as TNM classification (39). HPV-induced p16-positive OPSCC is a distinct type of HNSCC with a generally favorable outcome compared with p16-negative OPSCC, which may be independent of the treatment modality chosen. In the present study, we did not examine the association of p16-positive OPSCC with survival. Further studies are needed to assess these associations.

In previous studies, p53 overexpression, which reflects mutations in $\mathrm{p} 53$, has been shown to be associated with aggressive clinical course in several types of cancer, including OPSCC, gastric cancer, and colorectal cancer $(20,40,41)$. In the present study, p53 was frequently found to have a high PR (almost equivalent to overexpression) in HPV-negative OPSCC compared with that in HPV-positive OPSCC. A previous study showed that p53 overexpression was a predictive and prognostic factor in locally advanced pharyngeal cancer treated with induction chemotherapy (42). Therefore, the present results suggested that patients with HPV-positive OPSCC had better prognoses than patients with HPV-negative OPSCC. In addition, Shinohara et al indicated that a group of patients with p16-positive/p53-negative tumors had better overall survival 
and disease-specific survival (43). This finding was supported by our results showing that HPV-negative OPSCC showed higher expression of p53 and lower expression of p16 than HPV-positive OPSCC, supporting the poor prognosis.

The cyclin kinase inhibitor $\mathrm{p} 27$ is a central regulator of the cell cycle $(15,16)$. Overexpression of p27 arrests cells in the G1 phase, whereas loss of p27 leads to an increase in cell proliferation $(15,16)$. The degradation of $\mathrm{p} 27$ at the G1-S transition is mediated by SKP2, which shows an inverse expression pattern relative to that of p27 in cells (18). Previous studies have shown that low expression of p27 is correlated with poor prognosis in patients with gastric, breast, and prostate cancers (44-46). Thus, this finding suggested that high expression of p27 predicted a favorable prognosis in HPV-positive OPSCC. Additionally, we examined the relationship between p21 expression and HPV-positive OPSCC. Low expression of $\mathrm{p} 21$ is found in various cancers, including gastric and colorectal cancers $(20,47)$. In colorectal cancer, low expression of p21 is closely associated with tumor progression. However, the present results showed that there were no differences in p21 expression levels between HPV-positive and -negative OPSCC, suggesting that low p21 expression may be a common tumorigenic mechanism in both HPV-positive and -negative OPSCC.

Previous studies have shown that overexpression of cyclin D1 is a potential prognostic marker in OPSCC (34). Indeed, cyclin D1 is commonly upregulated in various cancers, including esophageal and colorectal cancers $(48,49)$. In the present study, our findings suggested that cyclin D1 expression was downregulated in HPV-positive OPSCC, possibly as a result of $\mathrm{p}-\mathrm{Rb}$ suppression (34). In addition, a previous study showed that cyclin D1 negativity was associated with p16 overexpression in OPSCC. This inverse relationship is consistent with the hypothesis that HPV positivity and subsequent p16 upregulation leads to suppression of cyclin D1 expression (34). In contrast, the expression of cyclin $\mathrm{A}$, which promotes tumor proliferation, did not differ between HPV-positive and HPV-negative OPSCC. This finding suggested that overexpression of cyclin A may play a common role in the development of HPV-positive and HPV-negative OPSCC.

In conclusion, HPV detection was performed in 98 OPSCC samples using ISH- and PCR-based assays. Although there are some concerns that must be considered when interpreting HPV detection data, we did not find evidence of differences in HPV detection using ISH- and PCR-based assays in the present study. Moreover, while overexpression of p16 may be a useful marker for detection HPV infection in tumor cells, we suggest that the combination of ISH- and PCR-based assays may be most effective for accurate detection of HPV positivity. Overexpression of p16 is an important factor that may provide an explanation for the improved prognosis in patients with HPV-positive OPSCC. Furthermore, cell cyclerelated proteins may also be effective for identification of the molecular mechanisms of OPSCC pathogenesis according to HPV status.

\section{Acknowledgements}

We gratefully acknowledge the technical assistance of members of the Department of Molecular Diagnostic Pathology, Iwate Medical University. We also thank members of the Department of Pathology, Miyagi Cancer Center, the Department of Head and Neck Surgery, Iwate Medical University and Miyagi Cancer Center for their support.

\section{References}

1. Elrefaey S, Massaro MA, Chiocca S, Chiesa F and Ansarin M: HPV in oropharyngeal cancer: The basics to know in clinical practice. Acta Otorhinolaryngol Ital 34: 299-309, 2014.

2. Ausweger C, Burgschwaiger E, Kugler A, Schmidbauer R, Steinek I, Todorov Y, Thurnher D and Krapfenbauer K: Economic concerns about global healthcare in lung, head and neck cancer: Meeting the economic challenge of predictive, preventive and personalized medicine. EPMA J 1: 627-631, 2010.

3. Gale N, Michaels L, Luzar B, Poljak M, Zidar N, Fischinger J and Cardesa A: Current review on squamous intraepithelial lesions of the larynx. Histopathology 54: 639-656, 2009.

4. Kreimer AR, Clifford GM, Boyle P and Franceschi S: Human papillomavirus types in head and neck squamous cell carcinomas worldwide: A systematic review. Cancer Epidemiol Biomarkers Prev 14: 467-475, 2005.

5. van Monsjou HS, Balm AJ, van den Brekel MM and Wreesmann VB: Oropharyngeal squamous cell carcinoma: A unique disease on the rise? Oral Oncol 46: 780-785, 2010.

6. Mignogna MD, Fedele S and Lo Russo L: The World Cancer Report and the burden of oral cancer. Eur J Cancer Prev 13: 139-142, 2004.

7. Sedrak M and Rizzolo D: Understanding the link between HPV and oropharyngeal cancers. JAAPA 22: 42-46, 2009.

8. Gillison ML: Human papillomavirus-associated head and neck cancer is a distinct epidemiologic, clinical, and molecular entity. Semin Oncol 31: 744-754, 2004.

9. Adelstein DJ and Rodriguez CP: Human papillomavirus: Changing paradigms in oropharyngeal cancer. Curr Oncol Rep 12: 115-120, 2010.

10. Stransky N, Egloff AM, Tward AD, Kostic AD, Cibulskis K, Sivachenko A, Kryukov GV, Lawrence MS, Sougnez C, McKenna A, et al: The mutational landscape of head and neck squamous cell carcinoma. Science 333: 1157-1160, 2011.

11. Ang KK, Harris J, Wheeler R, Weber R, Rosenthal DI, Nguyen-Tân PF, Westra WH, Chung CH, Jordan RC, Lu C, et al: Human papillomavirus and survival of patients with oropharyngeal cancer. N Engl J Med 363: 24-35, 2010.

12. Guo M, Gong Y, Deavers M, Silva EG, Jan YJ, Cogdell DE, Luthra R, Lin E, Lai HC, Zhang W, et al: Evaluation of a commercialized in situ hybridization assay for detecting human papillomavirus DNA in tissue specimens from patients with cervical intraepithelial neoplasia and cervical carcinoma. J Clin Microbiol 46: 274-280, 2008.

13. Pannone G, Rodolico V, Santoro A, Lo Muzio L, Franco R, Botti G, Aquino G, Pedicillo MC, Cagiano S, Campisi G, et al: Evaluation of a combined triple method to detect causative HPV in oral and oropharyngeal squamous cell carcinomas: p16 immunohistochemistry, consensus PCR HPV-DNA, and in situ hybridization. Infect Agent Cancer 7: 4, 2012.

14. Stein AP, Saha S, Kraninger JL, Swick AD, Yu M, Lambert PF and Kimple RJ: Prevalence of human papillomavirus in oropharyngeal cancer: A systematic review. Cancer J 21: 138-146, 2015.

15. Williams GH and Stoeber K: The cell cycle and cancer. J Pathol 226: 352-364, 2012.

16. Williams GH and Stoeber K: Cell cycle markers in clinical oncology. Curr Opin Cell Biol 19: 672-679, 2007.

17. Malumbres M and Barbacid M: Cell cycle, CDKs and cancer: A changing paradigm. Nat Rev Cancer 9: 153-166, 2009.

18. Lee Y and Lim HS: Skp2 inhibitors: Novel anticancer strategies. Curr Med Chem 23: 2363-2379, 2016.

19. Qiu L, Lv J, Chen Y, Wang J and Wu R: Expression of Skp2 and p2 $7^{\text {kipl }}$ proteins in hypopharyngeal squamous cell carcinoma and its clinical significance. Oncol Lett 10: 3756-3760, 2015.

20. Sugai T, Tsukahara M, Endoh M, Shioi Y, Takebe N, Mue Y, Matsushita H, Toyota M and Suzuki K: Analysis of cell cyclerelated proteins in gastric intramucosal differentiated-type cancers based on mucin phenotypes: A novel hypothesis of early gastric carcinogenesis based on mucin phenotype. BMC Gastroenterol 10: 55, 2010.

21. Juríková M, Danihel L', Polák Š and Varga I: Ki67, PCNA, and MCM proteins: Markers of proliferation in the diagnosis of breast cancer. Acta Histochem 118: 544-552, 2016. 
22. Ko E, Kim Y, Park SE, Cho EY, Han J, Shim YM, Park J and Kim DH: Reduced expression of cyclin D2 is associated with poor recurrence-free survival independent of cyclin D1 in stage III non-small cell lung cancer. Lung Cancer 77: 401-406, 2012.

23. Bahnassy AA, Zekri AR, El-Houssini S, El-Shehaby AM, Mahmoud MR, Abdallah S and El-Serafi M: Cyclin A and cyclin D1 as significant prognostic markers in colorectal cancer patients. BMC Gastroenterol 4: 22, 2004.

24. Boscolo-Rizzo P, Pawlita M and Holzinger D: From HPV-positive towards HPV-driven oropharyngeal squamous cell carcinomas. Cancer Treat Rev 42: 24-29, 2016.

25. Miller DM, Thomas SD, Islam A, Muench D and Sedoris K: c-Myc and cancer metabolism. Clin Cancer Res 18: 5546-5553, 2012.

26. Inwald EC, Klinkhammer-Schalke M, Hofstädter F, Zeman F, Koller M, Gerstenhauer M and Ortmann O: $\mathrm{Ki}-67$ is a prognostic parameter in breast cancer patients: Results of a large populationbased cohort of a cancer registry. Breast Cancer Res Treat 139: 539-552, 2013.

27. Li LT, Jiang G, Chen Q and Zheng JN: Ki67 is a promising molecular target in the diagnosis of cancer (Review). Mol Med Rep 11: 1566-1572, 2015.

28. Kuo KT, Hsiao CH, Lin CH, Kuo LT, Huang SH and Lin MC: The biomarkers of human papillomavirus infection in tonsillar squamous cell carcinoma-molecular basis and predicting favorable outcome. Mod Pathol 21: 376-386, 2008.

29. Izumo T, Kirita T, Ariji E, Ozeki S, Okada N, Okabe S, Okazaki Y, Omura K, Kusama M, Sato T, et al; Working Group 1 on the 'Guidelines for Clinical and Pathological Studies of Ora Cancer', Scientific Committee, Japan Society for Oral Tumors: General rules for clinical and pathological studies on oral cancer: A synopsis. Jpn J Clin Oncol 42: 1099-1109, 2012.

30. Cui M, Chan N, Liu M, Thai K, Malaczynska J, Singh I, Zhang D and Ye F: Clinical performance of Roche Cobas 4800 HPV Test. J Clin Microbiol 52: 2210-2211, 2014

31. Gage JC, Sadorra M, Lamere BJ, Kail R, Aldrich C, Kinney W, Fetterman B, Lorey T, Schiffman M and Castle PE; PaP Cohor Study Group: Comparison of the cobas Human Papillomavirus (HPV) test with the hybrid capture 2 and linear array HPV DNA tests. J Clin Microbiol 50: 61-65, 2012.

32. Stein AP, Saha S, Yu M, Kimple RJ and Lambert PF: Prevalence of human papillomavirus in oropharyngeal squamous cell carcinoma in the United States across time. Chem Res Toxicol 27: 462-469, 2014

33. Schache AG, Liloglou T, Risk JM, Filia A, Jones TM, Sheard J, Woolgar JA, Helliwell TR, Triantafyllou A, Robinson M, et al: Evaluation of human papilloma virus diagnostic testing in oropharyngeal squamous cell carcinoma: Sensitivity, specificity, and prognostic discrimination. Clin Cancer Res 17: 6262-6271, 2011.

34. Lin RJ, Lubpairee T, Liu KY, Anderson DW, Durham S and Poh CF: Cyclin D1 overexpression is associated with poor prognosis in oropharyngeal cancer. J Otolaryngol Head Neck Surg 42: 23, 2013.

35. Liu J, Zhang M, Rose B, Veillard AS, Jones D, Zhang X, Soon Lee C, Milross C and Hong A: Ki67 expression has prognostic significance in relation to human papillomavirus status in oropharyngeal squamous cell carcinoma. Ann Surg Oncol 22: 1893-1900, 2015 .
36. Lai S, Wenaas AE, Sandulache VC, Hartman C, Chiao E, Kramer J and Zevallos JP: Prognostic significance of p16 cellular localization in oropharyngeal squamous cell carcinoma. Ann Clin Lab Sci 46: 132-139, 2016.

37. Saber CN, Grønhøj Larsen C, Dalianis T and von Buchwald C: Immune cells and prognosis in HPV-associated oropharyngeal squamous cell carcinomas: Review of the literature. Oral Oncol 58: 8-13, 2016.

38. Yim EK and Park JS: The role of HPV E6 and E7 oncoproteins in HPV-associated cervical carcinogenesis. Cancer Res Treat 37: 319-324, 2005.

39. Fischer CA, Zlobec I, Green E, Probst S, Storck C, Lugli A, Tornillo L, Wolfensberger $\mathrm{M}$ and Terracciano LM: Is the improved prognosis of p16 positive oropharyngeal squamous cell carcinoma dependent of the treatment modality? Int J Cancer 126: 1256-1262, 2010.

40. Friedman JM, Stavas MJ and Cmelak AJ: Clinical and scientific impact of human papillomavirus on head and neck cancer. World J Clin Oncol 5: 781-791, 2014.

41. Sugai T, Nakamura SI, Habano W, Uesugi N, Sato H, Yoshida T and Orii S: Usefulness of proliferative activity, DNA ploidy pattern and p53 products as diagnostic adjuncts in colorectal adenomas and intramucosal carcinomas. Pathol Int 49: 617-625, 1999.

42. Lassaletta L, Brandáriz JA, Benito A, de la Cruz J, Gómez C, Ballestín C, Hitt R, Colomer R and Alvarez-Vicent JJ: p53 expression in locally advanced pharyngeal squamous cell carcinoma. Arch Otolaryngol Head Neck Surg 125: 1356-1359, 1999.

43. Shinohara S, Kikuchi M, Tona R, Kanazawa Y, Kishimoto I, Harada H, Imai Y and Usami Y: Prognostic impact of p16 and p53 expression in oropharyngeal squamous cell carcinomas. Jpn J Clin Oncol 44: 232-240, 2014.

44. Yang RM, Naitoh J, Murphy M, Wang HJ, Phillipson J, deKernion JB, Loda M and Reiter RE: Low p27 expression predicts poor disease-free survival in patients with prostate cancer. J Urol 159: 941-945, 1998.

45. Hayashi H, Ito T, Yazawa T, Ikeda M, Inayama Y, Nakatani Y, Kameda Y, Nakamura N and Kitamura H: Reduced expression of p27/Kip1 is associated with the development of pulmonary adenocarcinoma. J Pathol 192: 26-31, 2000.

46. Yasui W, Kudo Y, Semba S, Yokozaki H and Tahara E: Reduced expression of cyclin-dependent kinase inhibitor p27Kip1 is associated with advanced stage and invasiveness of gastric carcinomas. Jpn J Cancer Res 88: 625-629, 1997.

47. Mitomi H, Ohkura Y, Fukui N, Kanazawa H, Kishimoto I, Nakamura T, Yokoyama K, Sada M, Kobayashi K, Tanabe S, et al: P21WAF1/CIP1 expression in colorectal carcinomas is related to Kras mutations and prognosis. Eur J Gastroenterol Hepatol 19: 883-889, 2007.

48. Huang X-P, Rong T-H, Lin P, Wu Q-L, Yao G-Y, Hou J-H, Su X-D, Li X-D, Li B-J, Zhang P-Y, et al: Cyclin D1 overexpression in esophageal cancer from southern China and its clinical significance. Cancer Lett 231: 94-101, 2006.

49. Li Y, Wei J, Xu C, Zhao Z and You T: Prognostic significance of cyclin D1 expression in colorectal cancer: A meta-analysis of observational studies. PLoS One 9: e94508, 2014. 